\title{
Desenvolvimento e rendimento de soja em função da aplicação de ácido indol-butírico, ácido giberélico e cinetina
}

\section{Development and yield of soybean due to the application of indole-butyric acid, gibberellic acid and kinetin}

\section{Gederson Luiz Buzzello, Michelangelo Muzell Trezzi, Henrique von Hetwig Bittencourt, Felipe Patel, Edemir Miotto Junior}

Universidade Federal do Paraná, Rua XV de Novembro, 1299 - Centro, Curitiba - PR, 80060-000, email: gbuzzello@bol.com.br

Recebido em: 26/09/2014

Aceito em:25/07/2017

Resumo: Alguns reguladores de crescimento vegetal são capazes de modificar o desenvolvimento das plantas de soja, com reflexos no acamamento e no rendimento de grãos da cultura. Este trabalho teve por objetivo avaliar a injúria, altura, acamamento e rendimento de grãos em plantas de soja (Glycine max (L.) Merrill cv. CD 214 RR) após a aplicação via foliar de três doses de um fitoregulador composto por AIB, GA 3 e Cinetina. $\mathrm{O}$ experimento foi conduzido à campo em delineamento de blocos casualizados com quatro repetições. A aplicação do regulador de crescimento em todas as concentrações resultou em sintomas de fitotoxidade leve, logo após a aplicação, sendo que as plantas apresentaram recuperação dos sintomas de injúria rapidamente. Todos os tratamentos foram eficientes no controle do acamamento durante a maior parte do ciclo da cultura, ocasionado pela redução na altura das plantas em relação à testemunha. $\mathrm{O}$ tratamento com a maior dose de AIB, GA $\mathrm{G}_{3}$ Cinetina $\left(0,0375 ; 0,0375 ; 0,0675 \mathrm{~g} \mathrm{ha}^{-1}\right.$, respectivamente) foi aquele que apresentou o maior rendimento de grãos, influenciado por um aumento no número de grãos por vagem.

Palavras-chave: Glycine max (L.) Merrill, acamamento, altura de planta, injúria

Abstract: The development of soybean plants can be modified by some plant growth regulators, affecting lodging and grain yield. This study aimed to assess injury, plant height, lodging and grain yield in soybean (Glycine max (L.) Merrill cv. RR CD 214) after foliar application of three diferent rates of a plant growth regulator composed of IBA, $\mathrm{GA}_{3}$ and Kinetin. The experiment was conducted on a field using a randomized block design with four replications. The application of growth regulators in all tested concentrations resulted in mild symptoms of phytotoxicity after the application, but the plants recovered quickly. All treatments were effective in lodging control during most of the cycle, caused by the reduction in plant height compared to control. The treatment with the higher rateof IBA, GA 3 and Kinetin $\left(0.0375 ; 0.0375 ; 0.0675 \mathrm{~g} \mathrm{ha}^{-1}\right.$, respectively) was the one that showed the highest grain yield, wich was influenced by an increase in the number of seeds per pod.

Keywords: Glycine $\max (\mathrm{L}$.$) Merrill, lodging; plant height, injury$

\section{Introdução}

A soja é um dos principais produtos de exportação do Brasil e uma das principais commodities do mundo, sendo cultivada em $6 \%$ da terra arável do planeta. Sua proteína é muito utilizada na alimentação animal e seu óleo na alimentação humana e para obtenção de cosméticos, produtos de higiene, removedores de tinta e plásticos (Hartman et al., 2011; Pratap et al. 2012). Soma-se a isto o fato de que cresce linearmente a sua participação na alimentação humana e o seu potencial para a produção de biocombustíveis (Fore et al., 2011).

A cada ano, buscam-se novas tecnologias que propiciem aumento na produtividade da cultura da soja, que evitem perdas de rendimento de grãos e que permitam sua adaptação a diferentes cenários de mudanças climáticas. Nesse sentido, as causas das perdas de rendimento são diversas e ocorrem tanto antes quanto durante e após a colheita (Ainsworth et al., 2008; Varshney et al., 2011; Pratap et al., 2012). 


\section{Revista Agrarian}

ISSN: 1984-2538

Entre 80 e $85 \%$ das perdas de rendimento ocorrem durante a colheita dos grãos de soja, pela ação dos mecanismos da plataforma de corte das colhedoras (molinete, barra de corte e caracol). Cerca de $12 \%$ são ocasionadas pelos mecanismos internos (trilha, separação e limpeza) e 3\% são causadas por outros fatores, entre eles, a baixa altura de inserção de vagens e o acamamento das plantas que ocorrem na frente da plataforma de corte (Embrapa, 2008).

O acamamento também pode afetar diretamente o rendimento de grãos por interferir na acumulação de matéria seca, ou reduzir indiretamente o rendimento (Rocha, 1996; Lawn e James, 2011). O acamamento apresenta correlação positiva com a altura de planta e pode trazer sérios prejuízos à produção, ocasionando perdas de rendimento em cultivares de soja que podem atingir 10\% (Sherrie et al., 2011).

Em condições que propiciam grande desenvolvimento vegetativo da soja, as plantas tornam-se altamente suscetíveis ao acamamento. Com ele ocorre o sombreamento das folhas que antes recebiam radiação plena, causando desorganização do dossel (Mundstok e Thomas, 2005). As folhas sombreadas, com menor interceptação da radiação, apresentam maior razão respiração/fotossíntese do que aquelas com boa exposição solar, podendo se tornar drenos de fotoassimilados, o que pode reduzir a capacidade produtiva das plantas.

$\mathrm{O}$ acamamento também influencia a estrutura morfológica essencial para o uso eficiente de carboidratos e sua translocação para o grão e, quanto mais cedo ocorrer, maior será a redução no rendimento e na qualidade do grão (Zanatta e Oerlecke, 1991; Rocha, 1996; Lawn e James, 2011). A redução da qualidade do grão ocorre a partir de apodrecimento, que é facilitado com o aumento da proximidade do solo (Lobato, 2006).

Duas estratégias se apresentam na resolução do problema de acamamento na soja: a utilização de cultivares modernas com resistência ao acamamento (Lawn e James, 2011) e o uso de fitorreguladores (Buzzello et al., 2013). Como nem sempre as cultivares que apresentam resistência ao acamamento possuem conjuntamente alto potencial produtivo em determinadas condições ambientais, não se pode descartar o uso dos reguladores de crescimento.
Reguladores de crescimento de plantas ou fitorreguladores são todos os compostos químicos que diminuem a divisão e o alongamento celular em tecidos meristemáticos e regulam fisiologicamente a altura de planta (Cathey, 1964). Compostos sintéticos podem ser utilizados para reduzir o crescimento longitudinal indesejável da parte aérea das plantas, sem diminuição da produtividade de grãos (Rademacher, 2000). Os fitorreguladores são compostos utilizados em baixas concentrações, cuja resposta pode ser estimulatória ou inibitória sobre os processos de desenvolvimento vegetal (Vieira e Castro, 2004).

No entanto, os fitorreguladores também podem provocar algum tipo de injúria ou fitotoxidade às plantas, variando de acordo com a concentração utilizada ou grau de tolerância da espécie e da cultivar ao produto. É importante conhecer o comportamento relacionado à fitotoxidade de fitorreguladores em plantas de interesse, para permitir a avaliação do custobenefício dos mesmos.

Nesse contexto, esse trabalho teve por objetivo avaliar os efeitos da utilização de diferentes doses do regulador de crescimento (composto por uma combinação de $\mathrm{AIB}, \mathrm{GA}_{3} \mathrm{e}$ Cinetina) sobre injúria, altura, acamamento e rendimento de plantas de soja (Glycine max (L.) Merrill. cv. CD 214 RR).

\section{Material e Métodos}

O experimento foi conduzido em campo na Estação Experimental do Campus da Universidade Tecnológica Federal do Paraná, situada no município de Pato Branco - PR, com latitude de $26^{\circ} 10^{\prime} 27^{\prime} \mathrm{S}$, longitude de $52^{\circ} 41^{\prime} 10^{\prime \prime} \mathrm{W}$ e altitude de $720 \mathrm{~m}$. O clima do município segundo Köppen é Cfa - clima subtropical úmido mesotérmico (Maark, 2002). O solo da área experimental foi classificado como Latossolo Vermelho Distroférrico úmbrico (Bhering et al., 2008).

A cultivar de soja utilizada no experimento foi a CD $214 \mathrm{RR}$, cujos períodos após a emergência para atingir o florescimento $\left(\mathrm{R}_{1}\right)$ e colheita são, respectivamente, de 39 e 139 dias e a altura média de planta é de $122 \mathrm{~cm}$ (Coodetec, 2013).

O delineamento estatístico adotado foi blocos casualizados com quatro repetições. Os tratamentos consistiram na aplicação de diferentes quantidades $\left(250,500\right.$ e $750 \mathrm{ml} \mathrm{ha}$ ha $\left.^{-1}\right)$ da 


\section{Revista Agrarian}

ISSN: 1984-2538

associação dos fitorreguladores ácido indolbutírico (AIB) + ácido giberélico $\left(\mathrm{GA}_{3}\right)+$ cinetina, marca comercial Stimulate ${ }^{\circledR}$ à partir das recomendações de Dario et al. (2005), no estádio fenológico de desenvolvimento $\mathrm{V}_{7}$. As doses de ingrediente ativo de AIB $+\mathrm{GA}_{3}+$ cinetina, em $\mathrm{g}$ $\mathrm{ha}^{-1}$ foram de $0,0125+0,0125+0,0225$, $0,0250+0,0250+0,0450$ e $0,0375+0,0375+0,0675$, respectivamente.

As unidades experimentais continham cinco linhas de semeadura com 4,7 $\mathrm{m}$ de comprimento cada uma, espaçadas de $0,40 \mathrm{~m}$. A área útil das parcelas foi composta pelas duas linhas centrais, desconsiderando-se $0,5 \mathrm{~m}$ em cada extremidade. A semeadura foi realizada à profundidade de $0,05 \mathrm{~m}$ obtendo a densidade de 400.000 plantas $\mathrm{ha}^{-1}$. As densidades e épocas de semeadura utilizadas visaram maximizar o acamamento de plantas, tendo como base observações efetuadas em lavouras de soja da região Sudoeste do Paraná.

Os fitorreguladores foram aplicados com um equipamento de pulverização costal pressurizado com $\mathrm{CO}_{2}$, calibrado para uma vazão de $200 \mathrm{~L} \mathrm{ha}^{-1}$. Foram observados os cuidados relativos à aplicação dos fitorreguladores e demais defensivos necessários no decorrer do experimento, como umidade relativa do ar maior ou igual a $60 \%$, temperaturas na faixa de 19 a $30^{\circ} \mathrm{C}$ e velocidade do vento menor que $8 \mathrm{~km} \mathrm{~h}^{-1}$ (Costa, 1996). Foram observados, também, os intervalos recomendados entre a aplicação dos produtos e a ocorrência de chuvas, a fim de evitar a perda de eficácia dos fitorreguladores e dos demais produtos utilizados (inseticidas, fungicidas e herbicidas).

No decorrer do experimento, as principais pragas e doenças foram monitoradas e controladas segundo recomendações técnicas, para evitar danos significativos à cultura (Embrapa, 2005; Embrapa, 2008). O controle de plantas daninhas foi realizado através de duas aplicações do herbicida glyphosate $\left(720 \mathrm{~g} \mathrm{ea} \mathrm{ha}^{-1}\right)$.

As variáveis avaliadas no decorrer do ciclo da cultura foram injúria e altura de planta, em sete épocas $(7,14,21,28,35,42,49$ dias após sua aplicação) e acamamento em oito épocas distintas $(7,14,21,28,35,42,49$ e 56 dias após sua aplicação). Para a avaliação de altura, mediram-se dez plantas, aleatoriamente, na área útil da parcela.
A determinação do acamamento foi feita considerando-se a área útil, atribuindo notas correspondentes ao grau de acamamento observado, segundo a escala proposta por Bernard et al. (1965). Os valores variaram de 1 a 5 , conforme a seguinte caracterização: 1 para todas as plantas eretas; 2 para algumas plantas inclinadas; 3 para todas as plantas inclinadas ou 25 a $50 \%$ acamadas; 4 para todas as plantas severamente inclinadas ou 50 a $80 \%$ acamadas; e 5 para todas as plantas acamadas.

A injúria (toxicidade) na parte aérea da soja ocasionada pelos fitorreguladores foi avaliada com base na escala para avaliação visual de injúria causada por herbicidas, proposta por Frans et al. (1986).

Os dados das variáveis injúria, altura de planta e acamamento foram submetidos à análise da variância pelo teste $\mathrm{F}$. A relação entre as variáveis independente e dependente foi ajustada através de regressão polinomial. Foi realizado o teste de DMS $(p<0,10)$, para a comparação de médias das variáveis entre tratamentos. Também foi utilizado o teste de correlação de Pearson e a análise de trilha para as variáveis: altura de planta, acamamento, número de vagens por planta, número de grãos por vagem e rendimento. Os valores de injúria foram transformados segundo $\sqrt{ } \mathrm{x}+5$ e acamamento segundo $\sqrt{ } \mathrm{x}$.

Ao final do experimento foi realizada a colheita das parcelas (área útil de $4,05 \mathrm{~m}^{2}$ ) para determinação do rendimento de grãos. Uma amostra de um metro linear pertencente a esta área útil foi colhida separadamente para obtenção do número de plantas por metro quadrado, número de vagens por planta, número de grãos por vagem e peso de grão. Para a obtenção do rendimento de grãos e da massa de 1000 grãos, as massas dos mesmos foram corrigidas tendo como base a umidade de $13 \%$.

\section{Resultados e Discussão}

Injúria às plantas de soja

Na primeira época de avaliação (7 DAA), os tratamentos com $\mathrm{AIB}+\mathrm{GA}_{3}+$ cinetina apresentaram inúria leve (Frans et al., 1986), diferindo da testemunha, mas sendo igual entre todas as doses avaliadas. Na segunda época de avaliação, aos 14 DAA, as plantas de todos os tratamentos com $\mathrm{AIB}+\mathrm{GA}_{3}+$ cinetina apresentaram plena recuperação. A injúria promovida por 


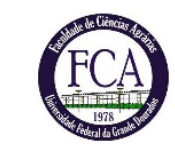

\section{Revista Agrarian}

ISSN: $1984-2538$

$\mathrm{AIB}+\mathrm{GA}_{3}+$ cinetina se caracterizou por uma pequena atrofia foliar, principalmente em folhas mais novas.

Avaliando o efeito do uso dos mesmos reguladores de crescimento sobre $\mathrm{O}$ desenvolvimento e o rendimento de soja (cv. IAC18), Rodrigues e Domingues (2002) não constataram a ocorrência de efeito deletério sobre as sementes, plântulas e plantas de soja. Em outro experimento também com soja (cv. CD 206) não foram constatados efeitos de toxidade, independente da forma de aplicação e dosagens avaliadas (Milléo, 2002). Como esses trabalhos utilizaram a mesma formulação e as mesmas concentrações de bioestimulante, é possível que a sensibilidade das cultivares ao bioestimulante e características ambientais distintas justifiquem a toxicidade observada em todos os tratamentos na primeira avaliação (7 DAA).

\section{Altura de planta}

A maior concentração de $\mathrm{AIB}+\mathrm{GA}_{3}+$ cinetina $\left(0,0375+0,0375+0,0675 \mathrm{~g}^{\mathrm{ha}^{-1}}\right)$ proporcionou maior redução na altura das plantas em relação a testemunha (Figura 1).

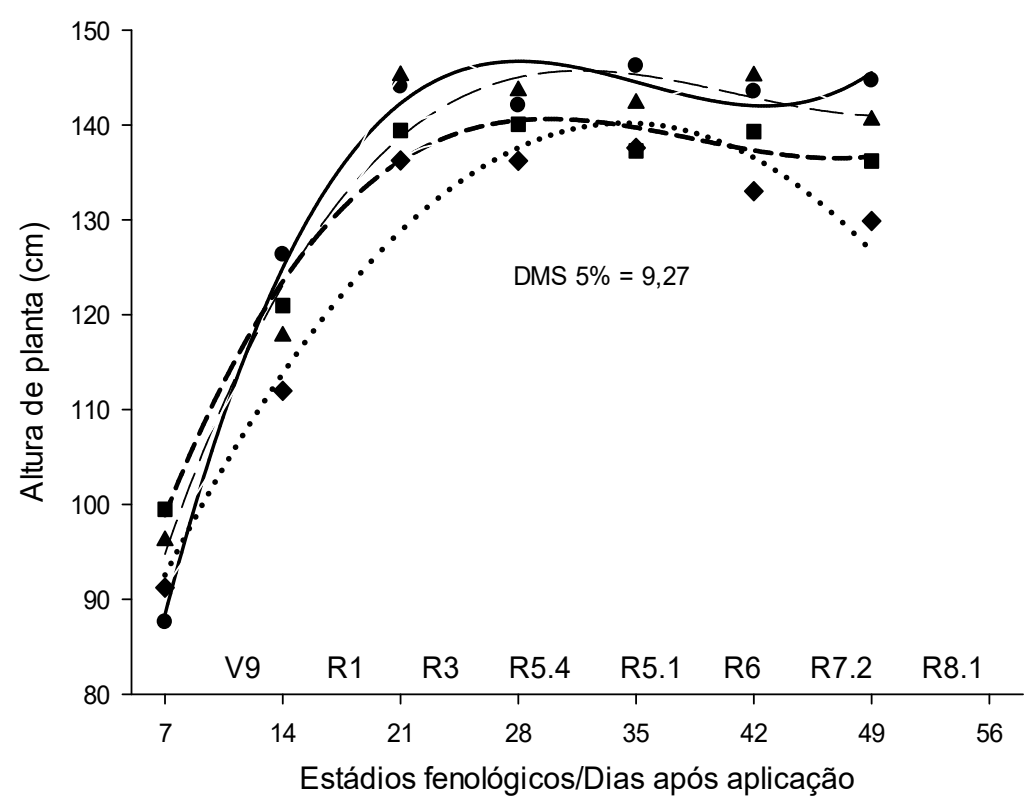

Figura 1. Altura de plantas de soja (Glycine max (L.) Merrill. cv. CD 214 RR), pela ação dos tratamentos com testemunha $(\bullet-)$ e bioestimulante (AIB+ $\mathrm{GA}_{3}+$ cinetina), em três concentrações: $\left(0,0125+0,0125+0,0225 \mathrm{~g} \mathrm{ha}^{-1}\right)(\mathbf{\Delta}----) ;\left(0,0250+0,0250+0,0450 \mathrm{~g} \mathrm{ha}^{-1}\right)(\mathbf{- - - - -}) ;(0,0375+0,0375+0,0675 \mathrm{~g}$ ha $\left.^{-1}\right)($ (*......) em função do estádio fenológico/época de avaliação.

$\mathrm{Na}$ segunda (14 DAA), na sexta (42 DAA) e na sétima avaliação (49 DAA), as reduções foram de 11,7 e $10 \%$, repectivamente. As alturas de plantas, em todos os tratamentos, se ajustaram a modelos cúbicos (Tabela 1). Já a menor concentração do regulador de crescimento $\left(0,0125+0,0125+0,0225 \mathrm{~g} \mathrm{ha}^{-1}\right)$ resultou em alturas de planta muito próximas da testemunha durante todas as avaliações realizadas ao longo do experimento. A concentração intermediária $\left(0,025+0,025+0,045 \mathrm{~g} \mathrm{ha}^{-1}\right)$ diferiu da testemunha na primeira avaliação (7 DAA), apresentando um valor de altura de planta $13 \%$ superior.

$\mathrm{Na}$ útima avaliação, efetuada aos 49 DAA, a redução percentual da estatura média das plantas foi diretamente proporcional à dose de Stimulate $^{\odot}$ (Figura 2). 


\section{Revista Agrarian}

ISSN: $1984-2538$

Tabela 1. Equações polinomiais e coeficientes de determinação dos tratamentos referentes à altura de plantas de soja pela ação dos tratamentos com bioestimulantes (AIB $+\mathrm{GA}_{3}+$ cinetina) em função do estádio fenológico/época de avaliação.

\begin{tabular}{lcc}
\hline \multicolumn{1}{c}{ Tratamento } & \multicolumn{1}{c}{ Equação polinomial } & $\mathrm{R}^{2}$ \\
\hline AIB+GA + cinetina $\left(0,0375+0,0375+0,0675 \mathrm{~g} \mathrm{ha}^{-1}\right)$ & $\hat{\mathrm{Y}}=89,848+33,368 \mathrm{X}-7,174 \mathrm{X}^{2}+0,452 \mathrm{X}^{3}$ & 0,9737 \\
AIB $+\mathrm{GA}_{3}+$ cinetina $\left(0,0250+0,0250+0,0450 \mathrm{~g} \mathrm{ha}^{-1}\right)$ & $\hat{\mathrm{Y}}=98,866+31,704 \mathrm{X}-7,654 \mathrm{X}^{2}+0,570 \mathrm{X}^{3}$ & 0,9802 \\
AIB $+\mathrm{GA}_{3}+$ cinetina $\left(0,0125+0,0125+0,0225 \mathrm{~g} \mathrm{ha}^{-1}\right)$ & $\hat{\mathrm{Y}}=94,776+35,696 \mathrm{X}-7,966 \mathrm{X}^{2}+0,55 \mathrm{X}^{3}$ & 0,9583 \\
Testemunha & $\hat{\mathrm{Y}}=88,392+48,241 \mathrm{X}-12,748 \mathrm{X}^{2}+1,049 \mathrm{X}^{3}$ & 0,9879 \\
\hline
\end{tabular}

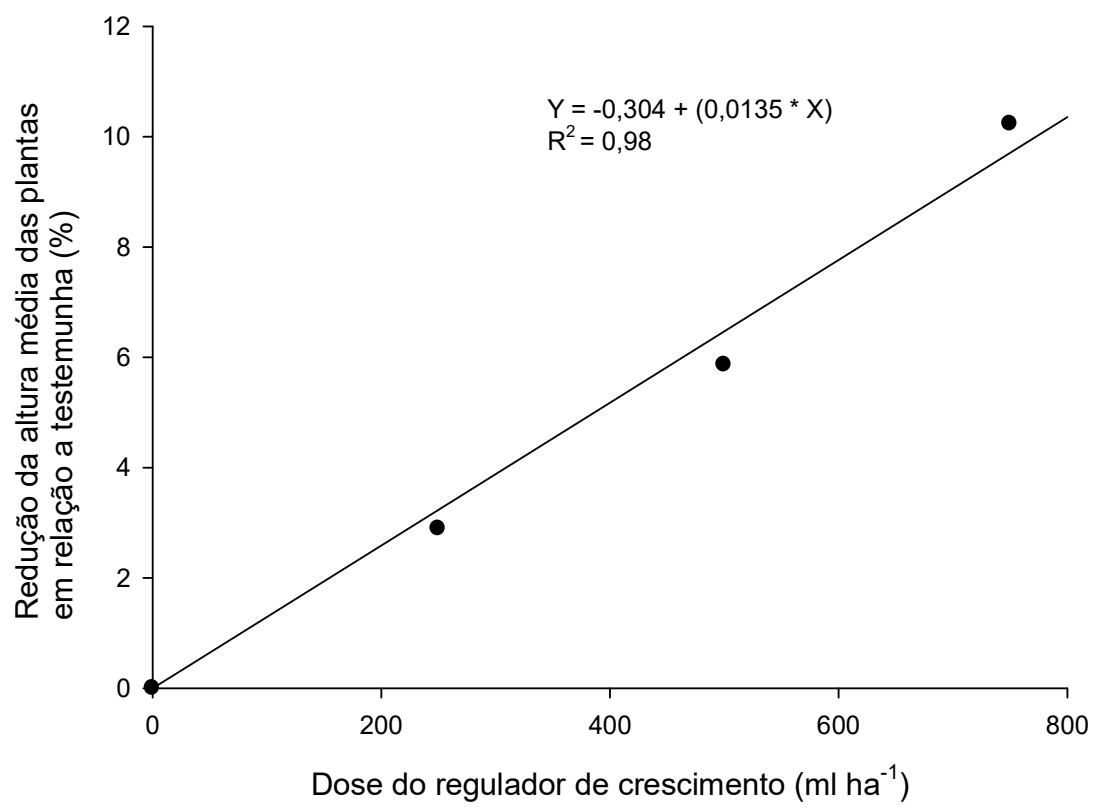

Figura 2. Redução (\% em relação à testemunha) da altura das plantas de soja (cv. CD 214 RR) em função da aplicação das diferentes doses de Stimulate ${ }^{\circ}$.

O resultado do teste de correlação de Pearson entre dose do regulador de crescimento e altura das plantas foi de $-0,76(\mathrm{p}<0,05)$ (Tabela 2), comprovando a relação inversamente proporcional observada, em que as maiores doses do regulador de crescimento resultaram em menores alturas de plantas em relação à testemunha na sétima e última avaliação (49 DAA).

Trabalho utilizando as mesmas concentrações de regulador de crescimento e forma de aplicação do que no presente experimento, relata que a altura de planta de soja (cv. Suprema) não foi influenciada pelo fitorregulador aplicado aos 43 DAE (Dario et al., 2005). Isso pode ter ocorrido poque a soja foi semeada próximo ao fotoperíodo crítico, o que limitou o desenvolvimento longitudinal das plantas de soja e, consequentemente, a ação do bioestimulante. 


\section{Revista Agrarian}

ISSN: $1984-2538$

Tabela 2. Valores do teste de correlação de Pearson para as variáveis: altura de planta, grau de acamamento, número de grãos por vagem e rendimento de grãos de soja.

\begin{tabular}{lccccc}
\hline & Dose de fitorreguladores & $\begin{array}{c}\text { Altura } \\
(\mathrm{cm})\end{array}$ & $\begin{array}{c}\text { Grau de } \\
\text { acamamento }\end{array}$ & $\begin{array}{c}\mathrm{N}^{\circ} \mathrm{de} \\
\text { grãos por } \\
\text { vagem }\end{array}$ & $\begin{array}{c}\text { Rendimento } \\
\left(\mathrm{kg} \mathrm{ha}^{-1}\right)\end{array}$ \\
\hline Dose de fitorreguladores & 1 & $-0,76^{*}$ & $-0,70^{*}$ & 0,20 & 0,36 \\
Altura $(\mathrm{cm})$ & $-0,76^{*}$ & 1 & $0,82^{*}$ & $-0,21$ & $-0,43^{* *}$ \\
Grau de acamamento & $-0,70^{*}$ & $0,82^{*}$ & 1 & $-0,15$ & $-0,45^{* *}$ \\
$\mathrm{~N}^{0}$ de grãos por vagem & 0,20 & $-0,21$ & $-0,15$ & 1 & 0,37 \\
Rendimento $\left(\mathrm{kg} \mathrm{ha}^{-1}\right)$ & 0,36 & $-0,43^{* *}$ & $-0,45^{* *}$ & 0,37 & 1 \\
\hline$* \mathrm{p}<0,05 ; * * \mathrm{p}<0,10$ & & & & &
\end{tabular}

\section{Acamamento de planta}

A relação entre o grau de acamamento e período de tempo após aplicação do dos tratamentos com $\mathrm{AIB}+\mathrm{GA}_{3}+$ cinetina se ajustou ao modelo quadrático positivo (Tabela 3). O grau de acamamento foi pequeno nas primeiras avaliações e atingiu o máximo entre 35 e 42 DAA. As diferentes concentrações de $\mathrm{AIB}+\mathrm{GA}_{3}+$ cinetina apresentaram resultados similares entre sí, reduzindo significativamente o acamamento em relação à testemunha na maior parte dos períodos de avaliação.

Tabela 3. Equações polinomiais e coeficientes de determinação dos tratamentos referentes ao acamamento em plantas de soja pela ação dos tratamentos com fitorreguladores (AIB $+\mathrm{GA}_{3}+$ cinetina) em função do estádio fenológico/época de avaliação.

\begin{tabular}{lcc}
\hline \multicolumn{1}{c}{ Tratamento } & Equação polinomial & $\mathrm{R}^{2}$ \\
\hline AIB $+\mathrm{GA}_{3}+$ cinetina $\left(0,0375+0,0375+0,0675 \mathrm{~g} \mathrm{ha}^{-1}\right)$ & $\hat{\mathrm{Y}}=0,677+1,436 \mathrm{X}-0,156 \mathrm{X}^{2}$ & 0,8161 \\
AIB $+\mathrm{GA}_{3}+$ cinetina $\left(0,0250+0,0250+0,0450 \mathrm{~g} \mathrm{ha}^{-1}\right)$ & $\hat{\mathrm{Y}}=0,568+1,975 \mathrm{X}-0,343 \mathrm{X}^{2}+0,018 \mathrm{X}^{3}$ & 0,7963 \\
AIB $+\mathrm{GA}_{3}+$ cinetina $\left(0,0125+0,0125+0,0225 \mathrm{~g} \mathrm{ha}^{-1}\right)$ & $\hat{\mathrm{Y}}=0,591+1,857 \mathrm{X}-0,308 \mathrm{X}^{2}+0,015 \mathrm{X}^{3}$ & 0,8204 \\
Testemunha & $\hat{\mathrm{Y}}=1,182+3,224 \mathrm{X}-0,839 \mathrm{X}^{2}+0,065 \mathrm{X}^{3}$ & 0,9617 \\
\hline
\end{tabular}

A maior concentração de AIB $+\mathrm{GA}_{3}+$ cinetina $\left(0,0375+0,0375+0,0675 \mathrm{~g}^{\text {ha }}{ }^{-}\right.$ $\left.{ }^{1}\right)$ apresentou capacidade superior de redução do acamamento em relação às demais concentrações apenas aos 56 DAA (Figura 3).

A maior eficácia na redução do acamamento foi observada no tratamento com a maior concentração de $\mathrm{AIB}+\mathrm{GA}_{3}+$ cinetina $\left(0,0375+0,0375+0,0675 \mathrm{~g} \mathrm{ha}^{-1}\right)$ (Figura 3$)$ e pode ser atribuída à sua capacidade em reduzir a altura das plantas (Figura 2). As variáveis altura de planta e acamamento apresentaram correlação positiva de 0,82 (Tabela 2 ) segundo teste de correlação linear de Pearson ( $\mathrm{p}<0,05)$.

A capacidade em reduzir a altura de planta, por sua vez, possivelmente está relacionada à maior concentração de citocinina (cinetina) nesse tratamento. Dentre os efeitos fisiológicos nas plantas, as citocininas podem estimular a divisão celular e o crescimento das gemas onde foram aplicadas. Dessa forma, os ramos produzidos a partir dessas gemas competem fortemente com o ramo principal, modificando a dominância apical (Campos et al., 2010; Taiz e Zeiger, 2004). 


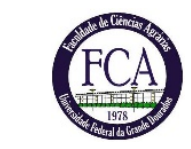

\section{Revista Agrarian}

ISSN: $1984-2538$

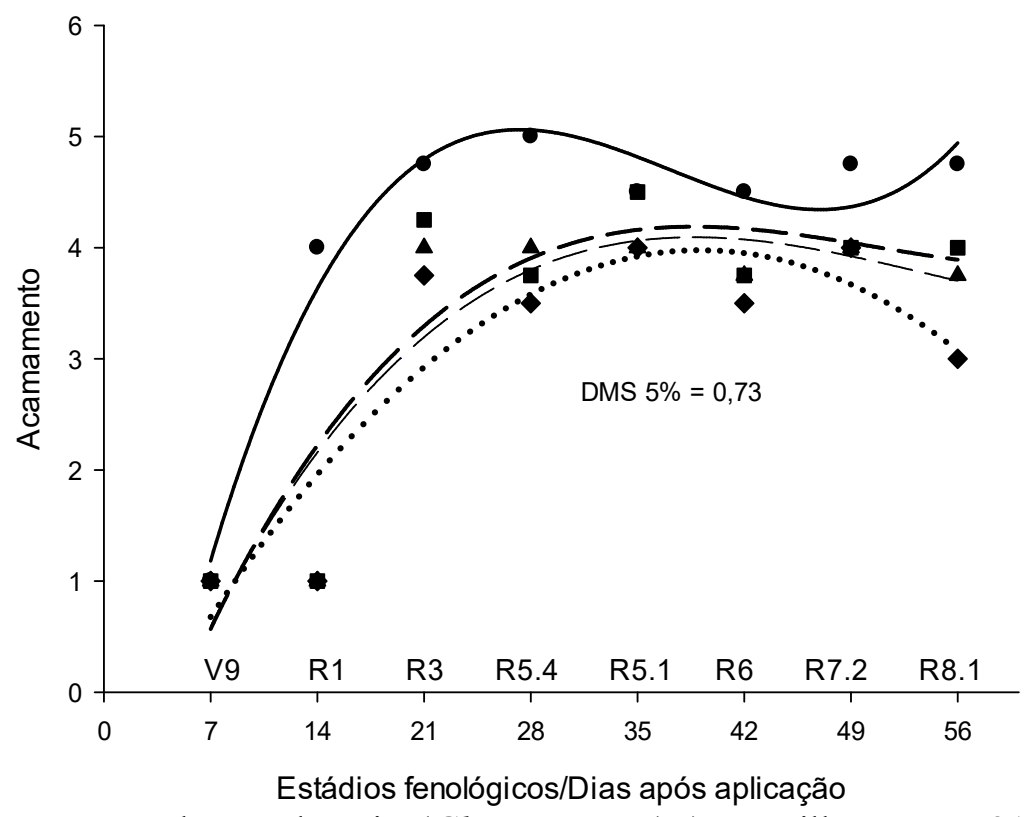

Figura 3. Acamamento em plantas de soja (Glycine max (L.) Merrill. cv. CD 214 RR), pela ação dos tratamentos testemunha $(\bullet-)$ e bioestimulante (AIB+ $\mathrm{GA}_{3}+$ cinetina), em três concentrações: $\left(0,0125+0,0125+0,0225 \mathrm{~g} \mathrm{ha}^{-1}\right)(\mathbf{\Delta}----) ;\left(0,0250+0,0250+0,0450 \mathrm{~g} \mathrm{ha}^{-1}\right)(\mathbf{- - - - -}) ;(0,0375+0,0375+0,0675 \mathrm{~g}$ ha $\left.^{-1}\right)(\star \cdots \cdots \cdots \cdot)$ em função do estádio fenológico/época de avaliação.

Número de plantas, vagens por planta, grãos por vagem, massa de 1000 grãos e rendimento

Não houve diferença entre os tratamentos quanto ao número de plantas por $\mathrm{m}^{2}$, nem quanto ao número de vagens por planta. Isso é importante porque, apesar de diminuir o porte das plantas, o bioestimulante não reduziu o estande ou a capacidade de produção de vagens (Tabela 4).

Tabela 4. Número de plantas por $\mathrm{m}^{2}$ (NP), número de vagens por planta (NVP), número de grãos por vagem $(\mathrm{GV})$, massa de 1000 grãos (PG, gramas) e rendimento de grãos (REND, $\mathrm{kg} \mathrm{ha}^{-1}$ ) de soja em função tratamentos com doses de fitorreguladores (AIB $+\mathrm{GA}_{3}+$ cinetina).

\begin{tabular}{lccccc}
\hline Tratamentos & $\mathrm{NP}^{1}$ & $\mathrm{NVP}^{1}$ & $\mathrm{GV}^{1}$ & $\mathrm{PG}^{1}$ & $\mathrm{REND}$ \\
\hline AIB+GA + cinetina $\left(0,0375+0,0375+0,0675 \mathrm{~g} \mathrm{ha}^{-1}\right)$ & 5,4 & 7,15 & $1,22 \mathrm{a}$ & 114,13 & $2437 \mathrm{a}$ \\
$\mathrm{AIB}+\mathrm{GA}_{3}+$ cinetina $\left(0,0250+0,0250+0,0450 \mathrm{~g} \mathrm{ha}^{-1}\right)$ & 5,6 & 7,7 & $1,10 \mathrm{~b}$ & 123,75 & $1850 \mathrm{~b}$ \\
$\mathrm{AIB}+\mathrm{GA}_{3}+$ cinetina $\left(0,0125+0,0125+0,0225 \mathrm{~g} \mathrm{ha}^{-1}\right)$ & 5,8 & 7,7 & $1,14 \mathrm{ab}$ & 113,69 & $1981 \mathrm{~b}$ \\
Testemunha $\left(0+0+0 \mathrm{~g} \mathrm{ha}^{-1}\right)$ & 5,8 & 8,0 & $1,16 \mathrm{ab}$ & 116,56 & $2111 \mathrm{~b}$ \\
\hline MÉDIAS & 5,6 & 7,6 & 1,3 & 117,0 & 2095 \\
C.V.\% & 9,23 & 14,22 & 15,95 & 8,91 & 12,80 \\
\hline
\end{tabular}

* Médias com mesma letra não diferem estatisticamente pelo teste DMS $(\mathrm{p}<0,10)$

${ }^{1}$ Dados transformados por $\sqrt{ } \mathrm{x}$

O número de grãos por vagem, no entanto, foi superior no tratamento com a maior concentração de ácido indol-butírico, ácido giberélico e cinetina. Esses resultados contrastam com os obtidos em trabalhos anteriores. Em um trabalho similarar testando oito fitoreguladores em plantas de soja (cv. BRS 184) não foi constatada influência sobre o número de grãos por vagem (Campos, 2005). Outros autores constataram que a aplicação de $\mathrm{AIB}+\mathrm{GA}_{3}+$ cinetina na maior concentração $\left(0,00375+0,00375+0,00675 \mathrm{~g} \mathrm{ha}^{-1}\right)$ via foliar não influenciou o número de grãos e de vagens por planta de soja (cv. CD 202) enquanto as demais concentrações avaliadas $(0,00125+0,00125+0,00225$

$\left.0,0025+0,0025+0,0045 \mathrm{~g} \mathrm{ha}^{-1}\right)$ resultaram em valores menores destas variáveis, em relação ao controle (Ávila et al., 2008).

$\mathrm{O}$ tratamento $\mathrm{AIB}+\mathrm{GA}_{3}+$ cinetina $\left(0,0375+0,0375+0,0675 \quad \mathrm{~g} \quad \mathrm{ha}^{-1}\right)$ apresentou 
rendimentos de grãos mais elevado em relação à testemunha e também em relação às demais concentrações de $\mathrm{AIB}+\mathrm{GA}_{3}+$ cinetina. A realização de análise de trilha para identificar a contribuição de cada um dos componentes sobre o rendimento revelou que o número de grãos por vagem apresentou efeito direto sobre $\mathrm{o}$ rendimento da cultura $(0,91)$, enquanto que o número de vagens por planta apresentou efeito indireto e de magnitude inferior $(0,07)$.

Relação direta e linear entre a concentração de cinetina $\left(0-1 \mathrm{~g} \mathrm{ha}^{-1}\right)$, um dos componentes testados, e o rendimento de soja (cv. BRSGO Luziânia) foi obtido por Passos et al. (2010). Com isso as citocininas podem atuar desenvolvendo os cloroplastos e inibindo a degradação da clorofila e, assim, prolongando o período fotossintético da planta (Taiz e Zeiger, 2004), o que pode contribuir com a produção de sementes de soja.

Foi relatado efeito sinérgico entre giberelinas e citocininas, capaz de ocasionar atraso da senescência em soja (Vieira e Castro, 2004). Assim, é possível explicar o incremento no rendimento de grãos de soja proporcionado pela associação entre $\mathrm{AIB}+\mathrm{GA}_{3}+$ cinetina $\left(0,0375+0,0375+0,0675 \mathrm{~g} \mathrm{ha}^{-1}\right)$.

\section{Conclusões}

Em elevadas concentrações, os fitorreguladores do grupo bioestimulantes (AIB, $\mathrm{GA}_{3}$ e cinetina) apresentam boa eficácia na redução de altura de planta e acamamento, com grau de fitotoxidade leve e breve recuperação dos sintomas.

O uso de fitorreguladores na cultura da soja determina a redução na altura de plantas e consequentemente o seu acamamento, em uma relação diretamente proporcional.

$\mathrm{O}$ tratamento com $\mathrm{IBA}+\mathrm{GA}_{3}+$ cinetina $\left(0,0375+0,0375+0,0675 \mathrm{~g} \quad \mathrm{ha}^{-1}\right)$ apresentou rendimento de grãos mais elevado, em virtude de um acréscimo do número de grãos por vagem.

\section{Referências}

AINSWORTH, E. A.; ROGERS, A.; LEAKEY, A. D. B. Targets for Crop Biotechnology in a Future High- $\mathrm{CO}_{2}$ and High-O $\mathrm{O}_{3}$ World. Plant Physiology, v. 147, p. 13-19, 2008.

ÁVILA, M. R.; BRACCINI, A. L.; SCAPIM, C. A.; ALBRECHT, L. P.; TONIN, T. A.; STÜLP, M. Aplicação de fitorregulador, desempenho agronômico e qualidade de sementes de soja. Scientia agricola, v.65, n.6, p.604-612, 2008.

BERNARD, R. L.; CHAMBERLAIN, D. W.; LAWRENCE, R. D. Results of the cooperative uniform soybean tests. Washington: USDA, 1965.

BHERING, S. B.; SANTOS, H. G. Mapa de solos do Estado do Paraná: legenda atualizada. Rio de Janeiro: EMBRAPA/IAPAR. 2008. 74p.

BUZZELLO, G. L.; TREZZI, M. M.: MARCHESE, J. A.; XAVIER, E.; MIOTTO JUNIOR, E.; PATEL, F.; DEBASTIANI, F. Action of auxin inhibitors on growth and grain yield of soybean. Revista Ceres, v. 60, n. 5, p. 621-628, 2013.

CAMPOS, M. F. Efeitos de reguladores vegetais no desenvolvimento de planta de soja (Glycine $\max ($ L.) Merrill). 2005. 131 f. Tese (Doutorado em Ciências Biológicas) - Universidade Estadual Paulista, Botucatu, 2005.

CAMPOS, M. F.; ONO, E. O.; RODRIGUES, J. D. Arquitetura de plantas de soja e a aplicação de reguladores vegetais. Pesquisa Aplicada e Agrotecnologia, v. 3, n. 1, 2010.

CATHEY, H. M. Physiology of Growth Retarding Chemicals. Annual Review Plant Physiology. Beltsville, v.15, p.271-302, 1964.

COODETEC, Cooperativa Central de Pesquisa Agrícola. Características da CD 214 RR. Disponível em: $<$ http://www.coodetec.com.br/php/detalhes_cultiv ar.php?id=28>. Acesso em: 01 agosto de 2013.

COSTA, J. A. Cultura da Soja. Porto Alegre: Evangraf. 1996. 233p.

DARIO, G. J. A.; MARTIN, T. N.; NETO, D. D.; MANFRON, P. A.; BONNECARRÈRE, R. A. G.; CRESPO, P. E. N. Influência do uso de fitorregulador no crescimento da soja. Revista da FZVA, v.12, n.1, p. 63-70, 2005.

EMBRAPA. Tecnologias de produção de soja: região central do Brasil - 2009 e 2010. Londrina: Embrapa. 2008. 262p.

EMBRAPA. Tecnologias de produção de soja: Paraná - 2006. Londrina: Embrapa Soja, 2005. $208 \mathrm{p}$.

FORE, S. R.; PORTER, P.; LAZARUS, W. Net energy balance of small-scale on-farm biodiesel production from canola and soybean. Biomass and Bioenergy, v. 35, p. 2234-2244, 2011.

FRANS, R.; TALBERT, R.; MARX, D.; CROWLEY, H. Experimental design and techniques for measuring and analysing plant 


\section{(-) \\ Revista Agrarian \\ ISSN: 1984-2538}

responses to weed control practices. In: CAMPER, N. D. Research Methods in Weed Science. $3^{\text {rd }}$ Edition. Champaign: Southern Weed Science Society, 1986. p. 29-46.

HARTMAN, G. L.; WEST, E. D.; HERMAN, T. K. Crops that feed the World 2. Soybean worldwide production, use, and constraints caused by pathogens and pests. Food Security, v. 3, n. 1, p. 5-17, 2011.

LAWN, R. J.; JAMES, A. T. Application of physiological understanding in soybean improvement. I. Understanding phenological constraints to adaptation and yield potential. Crop and Pasture Science, v. 62, n. 1, p. 1-11, 2011. LOBATO, M. T. V. Desempenho agronômico de genótipos de trigo em diferentes regiões do Estado de São Paulo. 2006. 160 f. Dissertação (Mestrado em Agricultura Tropical e Subtropical) - Instituto Agronômico de Campinas, IAC, Campinas.

MAARK, R. Geografia física do Estado do Paraná. 3. ed. Curitiba: Imprensa Oficial, 2002.

MILLÉO, M. V. R. Avaliação da eficácia agronômica de diferentes doses e formas de aplicação de Stimulate na cultura da soja. Ponta Grossa: Universidade Estadual de Ponta Grossa, 2002. 16p.

MUNDSTOK, C. M.; THOMAS, A. L. Soja: fatores que afetam o desenvolvimento e o rendimento. Porto Alegre: Evangraf, 2005. 31 p. PASSOS, A. M. A.; REZENDE, P. M.; ALVARENGA, A. A.; BALIZA, D. P.; CARVALHO, E. R.; ALCÂNTARA, H. P. Yield per plant and other characteristics of soybean plants treated with kinetin and potassium nitrate. Ciência Agrotécnica, v. 35, n. 5, p. 965 -972, 2011.

PRATAP, A.; GUPTA, S. K.; KUMAR, J.; SOLANKI, R. K. Soybean. In: Technological Innovations in Major World Oil Crops, Volume 1 - Breeding. GUPTA, S. K. (Ed.). New York: Springer, 2012. p. 293-321.

RADEMACHER, Wilhelm. Growth retardants: Effects on gibberellin biosynthesis and other metabolic pathways. Annual Review of Plant Physiology and Plant Molecular Biology, v. 51, p.501-531, 2000.

RODRIGUES, J. D.; DOMINGUES, M. C. S. Incrementos de produtividade na cultura da soja (Glycine max L. Merrill) cultivar IAC-18 com a aplicação do fitorregulador Stimulate.
Botucatu: Instituto de Biociências da UNESP, 2002. 17p.

ROCHA, A. B. Características de genótipos de aveia e de trigo e suas relações com a quebra de colmos. Porto Alegre, 1996. 126p. Dissertação (Mestrado em Agronomia). Faculdade de Agronomia da Universidade Federal do Rio Grande do Sul.

SHERRIE, I.; KHALED, O.; WASHINGTON, E.; LAGE, P.; WOODS, S.; KANTARTZI, S. K.; MEKSEM, K.; LIGHTFOOT, D. A.; KASSEM, M. A. Evaluation of Several Agronomic Traits in 'Essex'By 'Forrest' Recombinant Inbred Line Population of Soybean [Glycine max (L.) Merr.]. Atlas Journal of Plant Biology, v. 1, n. 1, p. 1317, 2011.

TAIZ, L.; ZEIGER, E. Fisiologia vegetal. Porto Alegre: Artmed, 2006. $4^{\text {a }}$ Ed. 719 p.

VARSHNEY, R. K.; BANSAL, K. C.; AGGARWAL, P. K.; DATTA, S. K.; CRAUFURD, P. Q. Agricultural biotechnology for crop improvement in a variable climate: hope or hype? Trends in Plant Science, v. 16, n. 7, p. 363-371, 2011.

VIEIRA, E. L.; CASTRO, P. R. C. Ação de bioestimulante na cultura da soja (Glycine max (L.) Merrill). Cosmópolis: Stoller do Brasil, 2004. 47 p.

ZANATTA, A. C. A.; OERLECKE, D. Efeito de genes de nanismo sobre alguns caracteres agronômicos e morfológicos de Triticum aestivum (L.) Thell. Pesquisa Agropecuária Brasileira, v. 26 p. 1001-1016. 1991. 